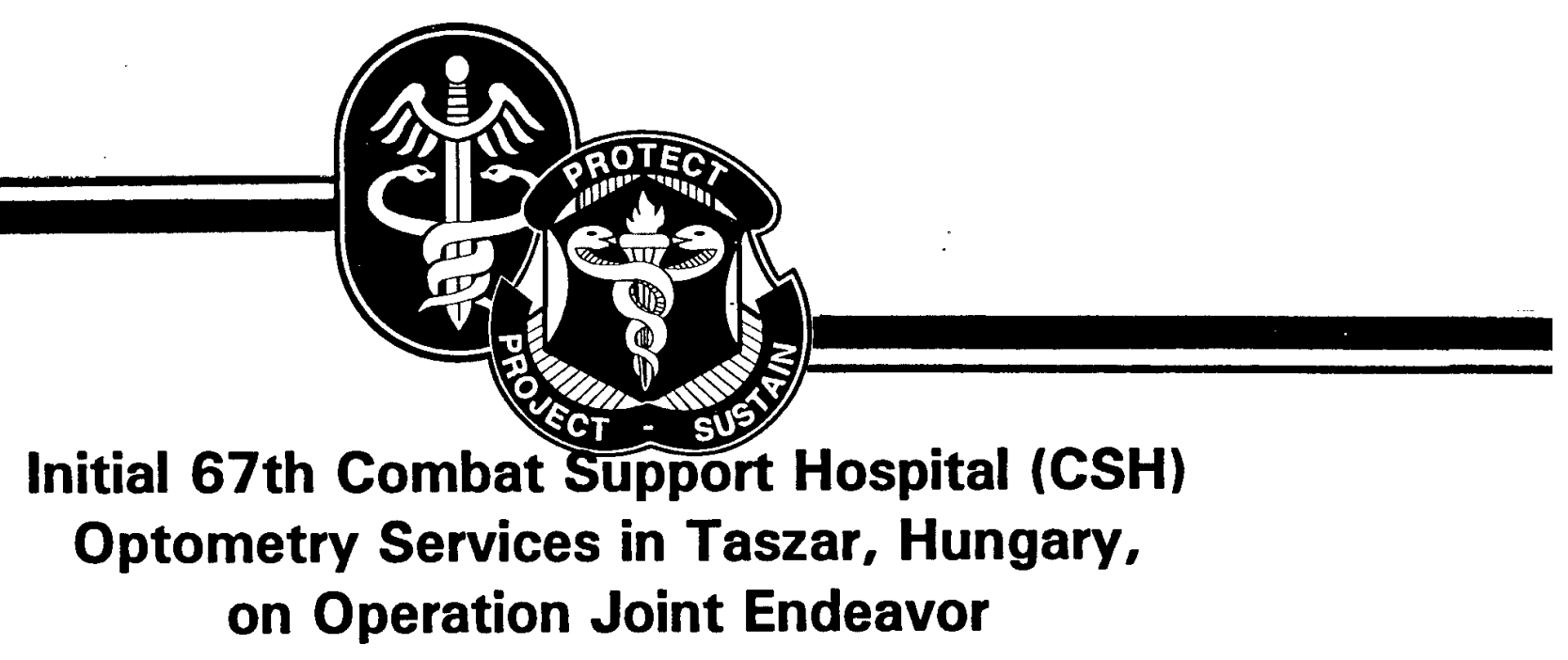

By

Dean Bancroft

710th Main Support Battalion

10th Mountain Division

Fort Drum, New York

and

Morris S. Lattimore

Aircrew Health and Performance Division

March 1999

19990420099

Approved for public release, distribution unlimited.

DTIC QUALITY INSPECTER 4

U.S. Army Aeromedical Research Laboratory

Fort Rucker, Alabama 36362-0577 
Notice

Qualified requesters

Qualified requesters may obtain copies from the Defense Technical Information Center (DTIC), Cameron Station, Alexandria, Virginia 22314 . Orders will be expedited if placed through the librarian or other person designated to request documents from DTIC.

\section{Change of address}

Organizations receiving reports from the U.S. Army Aeromedical Research Laboratory on automatic mailing lists should confirm correct address when corresponding about laboratory reports.

\section{Disposition}

Destroy this document when it is no longer needed. Do not return it to the originator.

\section{Disclaimer}

The views, opinions, and/or findings contained in this report are those of the author(s) and should not be construed as an official Department of the Army position, policy, or decision, unless so designated by other official documentation. Citation of trade names in this report does not constitute an official Department of the Army endorsement or approval of the use of such commercial items.

\section{Human use}

Human subjects participated in these studies after giving their free and informed voluntary consent. Investigators adhered to AR 70-25 and USAMRMC Reg 70-25 on Use of Volunteers in Research.

Reviewed:

\section{Rhat mhesplpie. \\ fi, MORRIS R. LATTIMORE, JR. \\ Colonel, MS \\ Director, Aircrew Health \& \\ Performance Division}

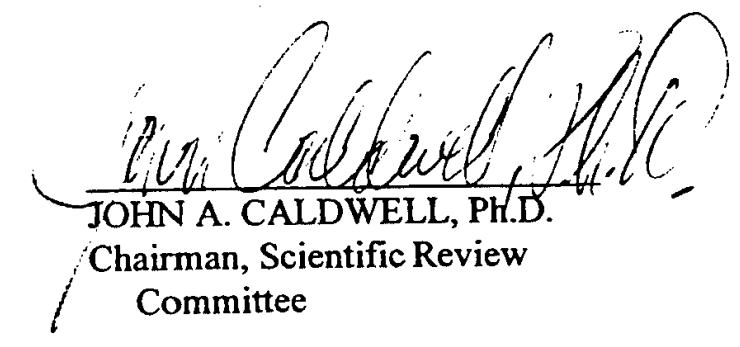

Released for publication:

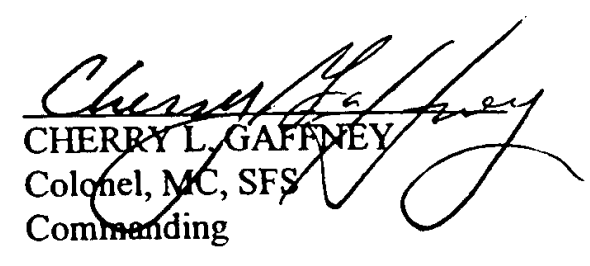


Unclassified

SECURITY CLASSIFICATION OF THIS PAGE

\section{REPORT DOCUMENTATION PAGE}

\section{1a. REPORT SECURITY CLASSIFICATION \\ Unclassified}

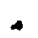

2a. SECURITY CLASSIFICATION AUTHORITY

2b. DECLASSIFICATION / DOWNGRADING SCHEDULE

4. PERFORMING ORGANIZATION REPORT NUMBER(S)

USAARI Report No. 99-13

6a. NAME OF PERFORMING ORGANIZATION

U.S. Army Aeromedical

Research Laboratory

6c. ADDRESS (City, State, and ZIP Code)

P.O. Box 620577

Fort Rucker, AL 36362-0577

8a. NAME OF FUNDING / SPONSORING ORGANIZATION

8C. ADDRESS (City, State, and ZIP Code)

\section{1b. RESTRICTIVE MARKINGS}

3. DISTRIBUTION / AVAILABILITY OF REPORT

Approved for public release, distribution unlimited

5. MONITORING ORGANIZATION REPORT NUMBER(S)

6b. OFFICE SYMBOL

(If applicable)

MCMR-UAS 7a. NAME OF MONITORING ORGANIZATION

U.S. Army Medical Research and Materiel Command

7b. ADDRESS (City, State, and ZIP Code)

Fort Detrick

Frederick, MD 21702-5012 8b. OFFICE SYMBOL (If applicable)
9. PROCUREMENT INSTRUMENT IDENTIFICATION NUMBER

10. SOURCE OF FUNDING NUMBERS

\begin{tabular}{l|l|l|l|}
$\begin{array}{l}\text { PROGRAM } \\
\text { ELEMENT NO. }\end{array}$ & $\begin{array}{l}\text { PROJECT } \\
\text { NO. }\end{array}$ & $\begin{array}{l}\text { TASK } \\
\text { NO. }\end{array}$ & $\begin{array}{l}\text { WORK UNIT } \\
\text { ACCESSION NO. }\end{array}$ \\
$62787 \mathrm{~A}$ & $30162787 \mathrm{~A} 879$ & PE & DAOB6893 \\
\hline
\end{tabular}

11. TITLE (Include Security Classification)

(U) Initial 67 th Combat Support Hospital (CSH) Optometry Services in Taszar, Hungary, on Operation Joint Endeavor

12. PERSONAL AUTHOR(S)

D. Bancroft; M. Lattimore

\begin{tabular}{c|c|c|c}
\hline $\begin{array}{c}\text { 13a. TYPE OF REPORT } \\
\text { Final }\end{array}$ & $\begin{array}{l}\text { 13b. TIME COVERED } \\
\text { FROM DeC } 95\end{array}$ TO Sep 96 & $\begin{array}{c}\text { 14. DATE OF REPORT (Year, Month, Day) } \\
1999 \text { March }\end{array}$ \\
\hline
\end{tabular}

16. SUPPLEMENTAL NOTATION

\begin{tabular}{|l|c|c|}
\hline 17. & \multicolumn{3}{|c|}{ COSATI CODES } \\
\hline FIELD & GROUP & SUB-GROUP \\
\hline 01 & 03 & \\
\hline 09 & 05 & \\
\hline
\end{tabular}

18. SUBJECT TERMS (Continue on reverse if necessary and identify by block number)

TO\&E, optometry, ocular injury and disease, CSH

19. ABSTRACT (Continue on reverse if necessary and identify by block number)

Existing U.S. Army personnel and equipment authorization documents do not currently

recognize the need for optometry services at deployed Combat Support Hospitals (CSHs).

The specific hospital tasked with the mission of supporting Operation Joint Endeavor (OJE)

from a support base in Taszar, Hungary, also did not have any documentation authorizing

the assignment of ophthalmology assets. Current Army doctrine stipulates the presence of

an Area Support Medical Battalion (ASMB), with assigned optometry assets, to deploy and

operate near a CSH. However, in the winter of 1995, when OJE began, there were no ASMBs staffed in Europe, and none deployed to the Taszar support base. Therefore, the 67th

CSH's mission of providing comprehensive in- and outpatient care on a contingency basis to all personnel in the area of operations did not have a doctrinal means of supporting an eyecare requirement. In order to meet this eyecare shortfall between doctrinal policy and actual operational needs or requirements, the optometry staff of the 67 th CSH scavenged two optometry field sets from old Desert Storm war-stock, and deployed with the main body of hospital personnel to Taszar, Hungary, on December 18th, 1995. In doing so, the Table of Organization and Equipment (TO\&E) was thus supplemented with (continued on next page)

20. DISTRIBUTION / AVAILABILITY OF ABSTRACT
$\triangle$ UNCLASSIFIED/UNLIMITED $\square$ SAME AS RPT.

22a. NAME OF RESPONSIBLE INDIVIDUAL

Chief, Science Support Center

DD Form 1473, JUN 86

21. ABSTRACT SECURITY CLASSIFICATION

Unclassified

22b. TELEPHONE (Include Area Code) 22c. OFFICE SYMBOL

(334) $255-6907$

MCMR-UAX-SS

SECURITY CLASSIFICATION OF THIS PAGE

Unclassified 


\section{Abstract (Continued)}

extra equipment and personnel, beyond doctrinal guidelines, in order to accomplish the assigned mission. This report is a prospectively gathered summary of the eyecare provided during the period 18 December 1995 through 15 September 1996. A total of 1,471 patients were examined and treated, averaging 7 patients per day. Under half of the case load was medical in nature, with the remaining being refractive in nature, or a periodic examination. The most common pathologies seen were: soft contact lens complications, noncontact lens corneal pathology, conjunctivitis (bacterial, viral, and adenoviral) and ocular trauma (foreign bodies, chemical splashes, and blunt injury). Refractive cases over the entire deployment were primarily myopes requiring increased correction. However, close to half the refractive cases in the first month were habitually uncorrected low hyperopes and early presbyopes. Based on the productivity presented by the case load demand of this CSH's area medical support mission, an eyecare need was clearly met, adding to the overall mission success of the 67 th CSH. 


\section{$\underline{\text { Acknowledgements }}$}

The authors wish to thank BG Porr, COL Bester, and LTC Sebastian for their dedicated support of our TO\&E operational interests. 
$\checkmark$ 


\section{Table of contents}

\section{Page}

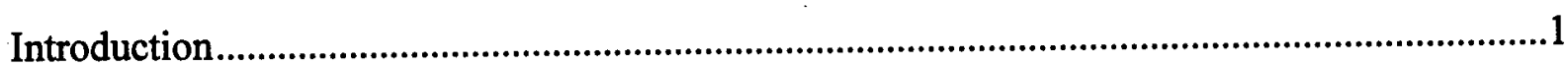

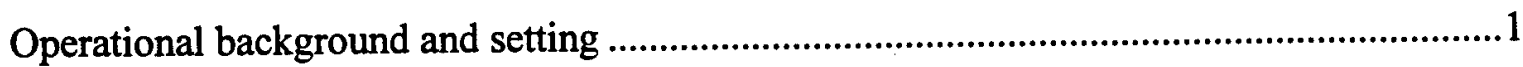

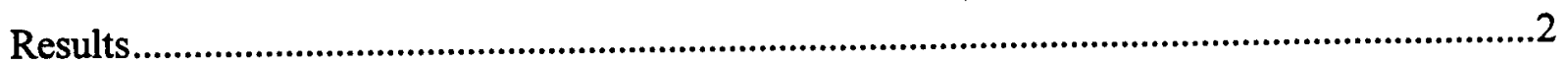

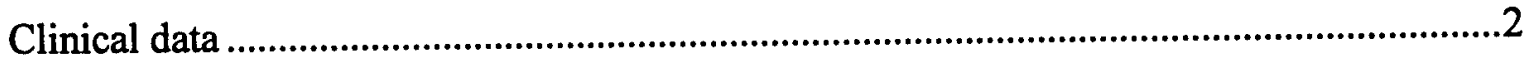

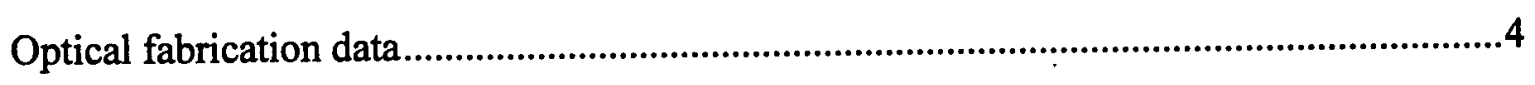

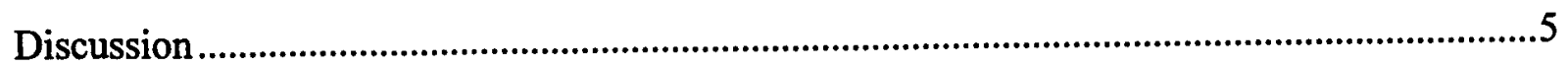

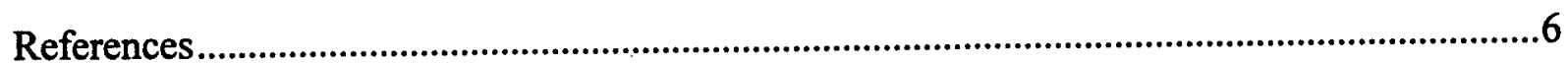


Introduction

The documented prevalence of ocular injury during time of war has increased steadily since the American Civil War. Ocular injuries represented 0.57 percent of all war injuries from 1861 - 1865 (Steindorf, 1914); several Middle East conflicts (1967, 1973, and 1982) exhibited a 7 percent prevalence of ocular injury (Treister, 1969; Hornblass, 1981; Belkin et al., 1984); and during Operation Desert Shield/Storm (ODS/S in 1990-91), 13 percent of all injuries were ocular in nature (Heier et al., 1993). Indeed, Heier et al., in their post Gulf War retrospective study, indicated that "Hospitals situated close enough to troops to receive acute injuries, should be equipped with a slit lamp and have at least one medical staff skilled in its use."

Given the operational uncertainties associated with Operation Joint Endeavor (OJE) in Bosnia, medical planners decided to deploy the 67th Combat Support Hospital (CSH) to Taszar, Hungary, in order to have specialized, hospital-based, in- and outpatient, contingency medical care readily available in the region. However, existing U.S. Army personnel and equipment authorization documents (Tables of Organization and Equipment or TO\&E) did not recognize the need for any eyecare services at deployed CSHs. Current Army doctrine stipulates the presence of an Area Support Medical Battalion (ASMB), with assigned optometry assets, to deploy and operate near a CSH. However, in the winter of 1995, when OJE began, there were no ASMBs staffed in Europe, and none deployed to the Taszar support base. Presented with the above information, $67^{\text {th }}$ CSH leadership opted to supplement their own TO\&E beyond doctrinal guidelines, when their optometry staff was able to scavenge two optometry field sets from old Desert Storm war- stock. The purpose of this article is to present and discuss the prospectively documented treatment the optometry service provided during this deployment. Other areas of TDA plus-up to the 67 th CSH (dental, blood lab, and physical therapy) have been documented previously in internal after-action reports.

\section{Operational background and setting}

Initially, two optometry officers and one ophthalmic technician deployed. Two months later, one optometry officer forward-filled into Bosnia. All patient visits were prospectively logged as to their chief complaint, diagnosis, and treatment. This deployable medical system (DEPMEDS) hospital was set up along the main runway of a former Soviet MiG Air Base at Taszar, Hungary. The airbase was used as an initial receiving and distribution point for personnel and equipment deploying to Bosnia. Situated in south-central Hungary, Taszar was a several hour ground convoy from the northern Croatian border at the Sava River, the initial point of ground entry into the former Yugoslavia.

The main body of hospital personnel left Germany on 18 December 1995, arriving in Hungary on 19 December 1995. Organizational and personal equipment had been shipped by rail earlier. The advance party had established the emergency room (ER) and organized the proposed hospital layout, so when the main party arrived, immediate construction of the hospital began. On 21 December, the optometry equipment was located in the rail car and shipping 
container storage area, and one slit lamp was established temporarily in the emergency room for emergent patient care until the clinic could be established. Full Optometry Clinic operations and all the other outpatient services of the $67^{\text {th }} \mathrm{CSH}$ began jointly on 29 December.

The data presented are cumulative from the beginning 21 December 1995 basic operational date until 15 September 1996, when the initially deploying members of the $67^{\text {th }} \mathrm{CSH}$ rotated back to Wuerzburg, Germany. A close comparison of these data with the Patient Administration Division (PAD) "Medical Summary Report" and "Incidence or Epidemiology Profile" roll-ups of $67^{\text {th }} \mathrm{CSH}$ operations may show some disagreement. Because the Optometry Service was a TDA add-on, the PAD initially did not have Optometry listed on either of their daily report forms, and neither solicited their input, nor reported their early data submissions. Consequently, it was approximately 4 weeks into the deployment before it was understood by the chain of command that both the PAD outpatient census and the Command epidemiology compendium were undercounting the CSH's actual workload.

Once the problem was understood, it took little time to fix the "Medical Summary Report" data, which were transmitted back to Germany by the same automated database that was used in Wuerzburg, correcting the daily census issue. However, the lost, initial, 4-week data were never captured retrospectively by that system, due to programming issues. The U.S. Army -Europe Medical Command's "Incidence or Epidemiology Profile" initially counted only eye disease and injury visits presenting to our ER. After we became aware of that report, about 4 weeks into the deployment, we began coordinating our disease and injury data with the ER and PAD.

Occasionally, disease and injury patients reached us through ER referral (usually nighttime, oncall emergencies), but most of the patients in those categories self-referred to our service (during normal operating hours from $0700-1900$ hours).

\section{$\underline{\text { Results }}$}

\section{Clinical data}

A total of 1,471 patients were seen during this 9 month (259 day) operating period. The figure illustrates the general patient distribution by categorization of complaint. Over half the patients presented with purely a refractive complaint (827); 428 patients presented with a request for a full examination, with no specific complaint; 48 patients were seen as a direct result of ocular trauma or injury; and 168 patients had visual or ocular complaints that were diagnosed as ocular disease (either purely ocular or secondary to systemic disease). The most common pathologies seen were: soft contact lens complications, noncontact lens corneal pathology, conjunctivitis (bacterial, viral, and adenoviral) and ocular trauma (foreign bodies, chemical splashes, and blunt injury). The table outlines the overall ocular injury and disease patient population from this deployment. 


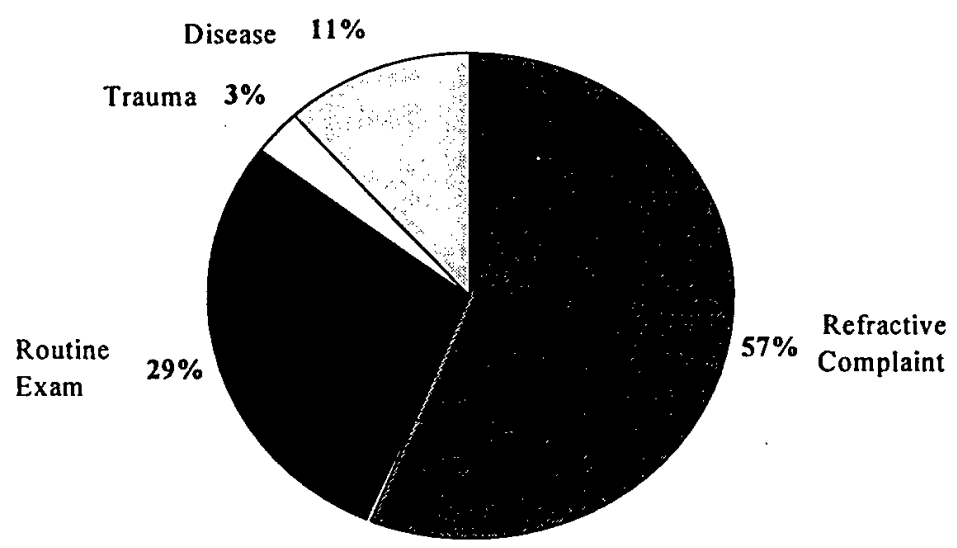

Figure. General Patient Distribution

There were four patients air evacuated to the 67th CSH optometry service from Slavonski Brod, Croatia, and Tuzla, Bosnia, during the deployment. All evacuated were soft contact lens wearers, each with a tentative diagnosis of corneal ulcer. All four patients exhibited the signs and symptoms of over-wear and presumed noninfective inflammatory toxicity (pain, conjunctival erythema, photophobia, and peripheral corneal subepithelial infiltrates). They all were treated with topical ophthalmic pharmaceutical drops that were a combination of antibiotic and steroid. After 3 days of treatment and close monitoring, they were returned to duty with instructions to taper the medication over the next 7 days, and to totally discontinue contact lens wear in the deployed environment.

There were nine patients (with ocular conditions) evacuated from the $67^{\text {th }} \mathrm{CSH}$. Eight of them were flown to the Landstuhl Army Regional Medical Center (LARMC), and one (a Brown and Root contract employee with an orbital fracture) was evacuated to an Oklahoma hospital near his home. Seven LARMC evacuations were routine, and one was an emergency evacuation. The emergency patient suffered a ruptured globe after accidentally being struck with a baseball bat. The seven routine evacuation diagnoses were: two cases of macular edema with macular holes, retinal infarct, inflammatory glaucoma (sarcoidosis), operculated retinal hole, diplopia of recent onset, and chorioretinitis. 
Table

Ocular Injury and Disease

Adnexia

Chalazion and/or hordeolum: $\quad 9$

Preseptal cellulitis:

Eyelid twitch:

Blepharitis:

Lid laceration:

Papilloma:

Contact dermatitis:

Ptosis:

Dermatochalasis:

Conjunctiva

Conjunctivitis:

(Bacterial: 16; Viral: 14;

Allergic: 10; Follicular: 1)

Subconjunctival hemorrhage:

Abrasion:

Hypersensitivity reaction:

Pinguecula:

Pterygium:

Phlyctenule:

Foreign body:

\section{Cornea}

Keratitis:

(viral: 9 [6 herpetic and $3 \mathrm{EKC}]$ exposure: 3; non-CL bacterial: 3; CL-related: 28)

Abrasion:

Foreign body:

(metallic: 4; non: 2 ;

unknown: 7)

41

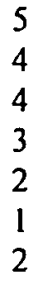

43

13

Refractive cases over the entire deployment primarily were myopes requiring increased correction. However, close to half the refractive cases in the first month were habitually uncorrected low hyperopes and early presbyopes. After the first month, the hyperopes and early presbyopes dropped to approximately 20 percent. It has been hypothesized that the long hours, fatigue, and other stresses associated with this Christmas-time deployment, made hyperopes and presbyopes disproportionately more subject to early deployment awareness of both decreased efficiency and amplitude of accomodation.

\section{Optical fabrication data}

There were 1301 pair of spectacles and/or protective mask optical inserts ordered during this deployment. All orders were transmitted electronically via the Spectacle Request Transmission System (SRTS) e-mail from a laptop computer, and were fabricated at the U.S. Army Medical Materiel Center - Europe (USAMMC-E) in Pirmasens, Germany. Spectacle orders then were shipped to Taszar, Hungary, from Germany via bi-weekly supply truck, and averaged 5.5 days turn-around time. 


\section{Discussion}

Fifty-seven percent of all patient visits were associated solely with refractive complaint, and 29 percent of all patient visits were for routine ocular evaluation and/or examination (e.g., annual IOP measurement, annual retinal assessment, or Class I, II, and III Flight Duty Medical Examinations). Without eyecare in-house, there would have been no recourse for medical personnel but to MEDEVAC these patients, or to contract to send them to a local Hungarian eyecare provider. Either option would have been at considerable expense, in terms of lost work time and/or actual dollar cost. Taking into account the full scope of eyecare provided, the deployment of these assets was likely the most cost effective option, as well as the best workable solution for this deployment.

Fourteen percent of all patient visits involved ocular injury or disease. This figure represents a slight, progressive, increase over Desert Storm data (Heier et al., 1993). However, this noncombat operation includes medically-related, non-trauma visits; a category not included in previous studies. Of important note is that the major medically-related subgrouping of patients was for contact lens-related pathology, even though ARs 40-5, 40-163, and 40-501 expressly forbid the wear of contact lenses in either the training or deployed field environment. While some of these patients could have been adequately managed by the ER or Family Practice physicians, neither of these specialties possessed detailed experience in corneal and contact lens pathologies, and neither specialty deployed with a slit lamp.

\section{Conclusions}

Clearly, the $67^{\text {th }} \mathrm{CSH}$ experience confirms the Desert Storm-based conclusions of Heier et al. (1993) regarding the deploying of a slit lamp and at least one medical care provider skilled in its use. In this specific case, individual initiative, combined with available personnel and material, provided a successful means for meeting the operational requirements of the mission. Finally, the 1,471 patient visits to the Optometry Service made it one of the busiest specialty areas in the hospital, giving considerable weight to the recommendation that Army doctrine should include an Optometry Service at deployed CSH's. 


\section{$\underline{\text { References }}$}

Belkin, M., Treister, G., and Doton, S. 1984. Eye injuries and ocular protection in the Lebanon War. Isr J Med Sci. 20: 333-338.

Heier, J. S., Enzenauer, R. W., Wintermeyer, S. F., Delaney, M., and LaPiana, F. P. 1993. Ocular injuries and diseases at a combat support hospital in support of Operations Desert Shield and Desert Storm. Arch Ophthalmol. 111: 795-798.

Hornblass, A. 1981. Eye injuries in the military. Int Ophthalmol Clin (Winter). 21: 121-138.

Steindorf, K. 1914. Berlin Klin Wochenschr. Die Kriegschirurgie des Schorganz. $51: 1787-1789$.

Treister, G. 1969. Ocular casualties in the 6-Day War. Am J Ophthalmol. 68(4): 669-673. 